\title{
Proceeding
}

Supplementary Issue: Autumn Conferences of Sports Science. Costa Blanca Sports Science Events, 18-19 December 2020. Alicante, Spain.

\section{Differentiation of physical education lessons by body mass index of schoolchildren}

\author{
ROMAN SERGEEVICH NAGOVITSYN ${ }^{1} \triangle$, ALEKSANDER YURIEVICH OSIPOV2,3 ${ }^{2}$ DENIS VASIL'EVICH \\ LOGINOV2,3,4,5, DMITRY SERGEEVICH PRIKHODOV 2,3,4, IRINA IGOREVNA ORLOVA ${ }^{3}$
}

${ }^{1}$ Glazov State Pedagogical University, Russian Federation

2 Siberian Federal University, Russian Federation

${ }^{3}$ Krasnoyarsk State Medical University named after professor V.F. Voyno-Yasenetsky, Russian Federation

${ }^{4}$ Reshetnev Siberian State University Science and Technology, Russian Federation

${ }^{5}$ Krasnoyarsk State Pedagogical University named after V.P. Astafyev, Russian Federation

\begin{abstract}
Background: Many methodological problems associated in a sports and fitness environment based on a differentiated approach remain beyond the interest of researchers and developers. The aim of the study was to differentiate physical education classes in school in terms of the individual body mass index of schoolchildren and experimentally prove the effectiveness of its implementation for the harmonious development of youth. Study participants: schoolchildren 15-17 years $(n=64)$. All the schoolchildren were divided into four groups using the method of body mass index (BMI). Interventions: Pedagogical research was carried out for 7 months at school. The study used tests "Ready for work and defense", BMI, body health indicator and cognitive rate. Main outcome measures. In schoolchildren from the groups (EG1 and EG2), differentiated by BMI for physical education classes, the results on physical qualities improved: endurance and dexterity $(p<.05)$. In CG1, where there was no differentiation, during the experiment 3 schoolchildren with overweight added. Thanks to the experimental intervention in EG1, the schoolchildren kept their initial BMI normal. Separate education of schoolchildren has a positive effect on the cognitive abilities of schoolchildren: comparison of EG1 and CG1 ( $p<.01)$, comparison of EG2 and CG2 $(p<.05)$. Findings. The study showed the effectiveness of the BMI in differentiating of youth into groups. If the differentiating physical education at school to indicators of BMI, it will significantly improve the performance of physical and cognitive abilities schoolchildren 15-17 years old and reduce obesity of youth.
\end{abstract}

Keywords: Physical education; BMI; Schoolchildren; Differentiation.

Cite this article as:

Nagovitsyn, R.S., Osipov, A.Y., Loginov, D.V., Prikhodov, D.S., \& Orlova, I.I. (2021). Differentiation of physical education lessons by body mass index of schoolchildren. Journal of Human Sport and Exercise, 16(2proc), S172-S181. doi:https://doi.org/10.14198/jhse.2021.16.Proc2.02

Corresponding author. Glazov State Pedagogical University, Russian Federation. http://orcid.org/0000-0003-4471-0875

E-mail: gto18@mail.ru

Abstract submitted to: Autumn Conferences of Sports Science. Costa Blanca Sports Science Events, 18-19 December 2020. Alicante, Spain.

JOURNAL OF HUMAN SPORT \& EXERCISE ISSN 1988-5202

(c) Faculty of Education. University of Alicante

doi:10.14198/jhse.2021.16.Proc2.02

S172

| 2021 | Proc2 | VOLUME 16

(C) 2021 University of Alicante 


\section{INTRODUCTION}

The increase in the pace of scientific and technological progress, the intensification of social changes affecting schoolchildren who need to adapt in the future to new conditions of life, requires the search for new methods for organizing physical education (Magdalena et al., 2016). As the most important sphere of culture responsible for preparing a person for a full life, for the formation of his physical and health potential (Galan et al., 2018; Laguna et al., 2013; Oliveira et al., 2017). One of the main conditions is the need to make fundamental changes to its traditional content, which in many cases is unpopular among schoolchildren (Lee et al., 2007; Riso et al., 2016). In this situation, a contradiction is found between a significant range of scientific physical culture and health studies that focus on self-improvement of physical culture training, and insufficient development of the technological and methodological foundations of this process (Aryana et al., 2012; Cvetković et al., 2018).

Many fundamental methodological problems associated with the design of pedagogical technologies in a sports and fitness environment based on a differentiated approach remain beyond the interest of researchers and developers (Khudolii et al., 2019; Nagovitsyn et al., 2019; Yagotin et al., 2019). Today, it is necessary to organize the physical education and health process of schoolchildren, aimed at improving their physical qualities, physique, physical health and fitness knowledge through the modernization of physical education classes (Riso et al., 2016; Song et al., 2016; Voloshina et al., 2018).

The special literature emphasizes the need to improve the health indicators of schoolchildren by means of active physical exercises, in particular the cardiovascular and respiratory systems (Osipov et al., 2016; Yarmak et al., 2018). Systematically and consistently implemented physical education classes increase immunity, contribute to the normalization of metabolism and other body systems (Oliveira et al., 2017). In this direction, experts emphasize the importance of physical education for schoolchildren to increase physique and prevent the initial signs of overweight and further obesity (Espinoza-Silva et al., 2019). In the aspect of physical preparation, experts prove the main influence in the harmonious development of all physical qualities through the modernization of physical education (Nagovitsyn et al., 2019). Some specialists place a special emphasis on the cognitive component of physical education in the implementation of physical activity (Laguna et al., 2013). It is a properly organized physical education for schoolchildren that will allow them to form their ability for conscious motor activity (Riso et al., 2016). According to experts, it is only through increasing the physical and health-improving knowledge of schoolchildren that it is possible for them to form a set of values in the field of a healthy lifestyle and full social adaptation (Donnelly et al., 2009; Magdalena et al., 2016). The implementation of this process based on the didactic possibilities of using individually differentiated technologies will increase its efficiency by improving the indicators of physical qualities, increasing the level of functional capabilities of schoolchildren and motivating adolescents to physical activity (Aoyama et al., 2018; Cvetković et al., 2018).

The lack of the necessary scientific and methodological base and human resources in each individual institution actualizes the problem of integrating pedagogical technologies focused on the introduction of an individually differentiated approach (Tanaka et al., 2018). Creates a need to improve the efficiency of the use of resources for the implementation of physical education (Nagovitsyn et al., 2017; Şar et al., 2018). Modernization of the physical education activities of schoolchildren on the basis of non-traditional and innovative approaches will provide modern needs and requirements of the younger generation (Grieco et al., 2009; Riso et al., 2016). In this aspect, the introduction of individually differentiated technologies into the process of forming a harmoniously physically developed personality will make it possible to ensure the effectiveness of the fitness and health process and, as a whole, will further increase the number of working- 
age population (Aryana et al., 2012; Nagovitsyn et al., 2018). Which ultimately plays a decisive role in a positive increase in the country's economic indicators (Nagovitsyn et al., 2019; Osipov et al., 2016).

Thus, the hypothesis of the study can be stated: the fitness and health process of schoolchildren will be effective if we differentiate the groups for physical education in terms of individual body mass index. The aim of the study is to differentiate physical education classes in school in terms of the individual body mass index of schoolchildren and experimentally prove the effectiveness of its implementation for the harmonious development of youth.

\section{MATERIAL AND METHODS}

The study was conducted in Russia, in the city of Glazov, schools № 1 and № 3. All procedures performed in studies involving human participants were in accordance with the ethical standards of the institutional and/or national research committee and with the 1964 Helsinki declaration and its later amendments or comparable ethical standards. Informed consent was obtained from all individual participants included in the study.

Sixty-four schoolchildren aged 15-17 years from the tenth grades took part in the pedagogical research. All schoolchildren were healthy and allowed physical training. The study was implemented over 7 months (September 2018 - March 2019) from the first to third academic quarters. All participants in the study before the experiment were analysed by individual body mass index (BMI). This value makes it possible to assess the degree of correspondence of the schoolchild's mass and height and, therefore, indirectly evaluate whether the mass is insufficient, normal or excessive. The formula is BMI $\mathrm{m} / \mathrm{h}^{2}$, where «m» is body weight in kilograms, «h» is height in meters (Dobashi, 2016; Song et al., 2016).

Schoolchildren of the tenth grade "A" and tenth grade "B" of school № 1 were differentiated into 2 groups for physical education in terms of the individual body mass index of schoolchildren, regardless of gender. The experimental group (EG1) included schoolchildren $(n=14)$ with a BMI - low $(<21)$. The experimental group (EG2) included schoolchildren $(n=21)$ with a BMl of average or high $(>21)$. In turn, schoolchildren of the tenth grade "A" and tenth grade "B" of school № 3 were differentiated into 2 groups according to indicators of the individual body mass index of schoolchildren, not for physical education, but only for comparing the results. The control group (CG1) included schoolchildren $(n=12)$ with a BMI of low $(<21)$. The control group (CG2) included schoolchildren $(n=17)$ with a BMI of average or high $(>21)$.

In each experimental group of school № 1, physical education classes were held separately from each other at different times with one teacher 3 times a week. At school № 3 physical education classes were held separately for classes "A" and "B" without differentiation according to the body mass index of schoolchildren at different times with one teacher 3 times a week. The curriculum in both schools included the study of initial ideas about the importance of physical education, the mastery of the ability to organize health-saving life activities, performing the simplest acrobatic and gymnastic combinations, as well as technical actions from basic sports, their use in game and competitive activities.

\section{RESULTS}

To monitor the level of harmonious development of children after the experiment, the following diagnostic procedures were used. 
1. Physical indicator. Analysis of the level of physical development of the research participants according to the standards of the complex "Ready for Work and for the Defense" (GTO) using the method of the tests. The analysis of the obtained data was carried out by the levels: high, medium and low. Each level is the compliance of the obtained indicators with the standards of the GTO complex: high (gold badge), average (silver or bronze badge) and low (without badge). Participants performed the following exercises: short distance running, mixed movement, shuttle running, throwing a target, pulling up, pushing up from the floor, lifting the abs, flexibility exercises, long jump, swimming and skiing (Rassadina, 1981).

2. Health indicator. To determine the level of physical health, the method was used. E.A. Pirogova, which allows for rapid assessment of the level of physical condition by an indicator of the circulatory system, according to the formula below: $X=\left(700-3^{*} \mathrm{HR}-2.5^{*} \mathrm{APd}+(\mathrm{APs}-\mathrm{APd}) / 3-2.7^{*} \mathrm{~A}+0,28^{*} \mathrm{~W}\right) /\left(350-2.7^{*} \mathrm{~A}+0.21^{*} \mathrm{G}\right)$, HR - heart rate, G - body growth, $\mathrm{cm} ; \mathrm{W}$ - body weight, $\mathrm{kg} ; \mathrm{A}$ - age, full years, APs - arterial systolic pressure, APd - arterial diystolic pressure. High level: $X \geq 0.8$; average level: $0.8>X>0.4$; low level: $X \leq 0.4$.

3. Cognitive indicator. During the educational process in physical education, grades were determined for students based on the study of the following main areas:

- The formation of initial ideas about the importance of physical culture for strengthening human health (physical, social and psychological);

- Improving knowledge about the positive impact of active physical exercises on human development (physical, intellectual, emotional, social),

- Development of understanding of physical culture as the main factor in successful study and socialization;

- Mastering the skills to organize health-saving life activities (daily routine, morning exercises, recreational activities, outdoor games, etc.);

- The formation of the ability to systematically monitor their physical condition, the amount of physical activity, health monitoring data (length and body weight, etc.), indicators of basic physical qualities;

- Interaction with peers according to the rules for outdoor games and competitions;

- Performing the simplest acrobatic and gymnastic combinations at a high quality level, characterization of the signs of technical performance;

- Performance of technical actions from basic sports, their use in game and competitive activities.

Performance was assessed on the basis of average academic scores for three quarters: " 5 " - high level, "4" - average level, "3" - low level.

4. Proportional indicator. Participants were analysed on an individual body mass index (BMI) at three levels: $>25$ - high level (obesity), $25 \geq \mathrm{BMI} \geq 21$ - average level (overweight), $<21$ - low level (norm).

Statistical processing of research results was carried out using the statistical analysis program SPSS20. For a quantitative analysis of the data obtained during the research, a chi square test was used (for $p<.05, p<$ $.01)$.

Before the experimental work (September 2018), the participants in the study of schools № 1 and № 3 were significantly equal in terms of the health indicator $(p>.05)$. According to the cognitive indicator, there was no comparative monitoring because the presented educational material was studied by schoolchildren only during the experiment. According to the proportional indicator, the study participants were differentiated for experimental work into four focus groups. Only on a physical indicator, preliminary diagnostics revealed a 
significant difference between schoolchildren in schools № 1 and № $3(p<.05)$. The results of physical tests were significantly higher among schoolchildren of school 3 (CG1 and CG2).

After the experiment (March 2019), the implementation of diagnostic procedures for all indicators determined: the following results (Figures 1-4):

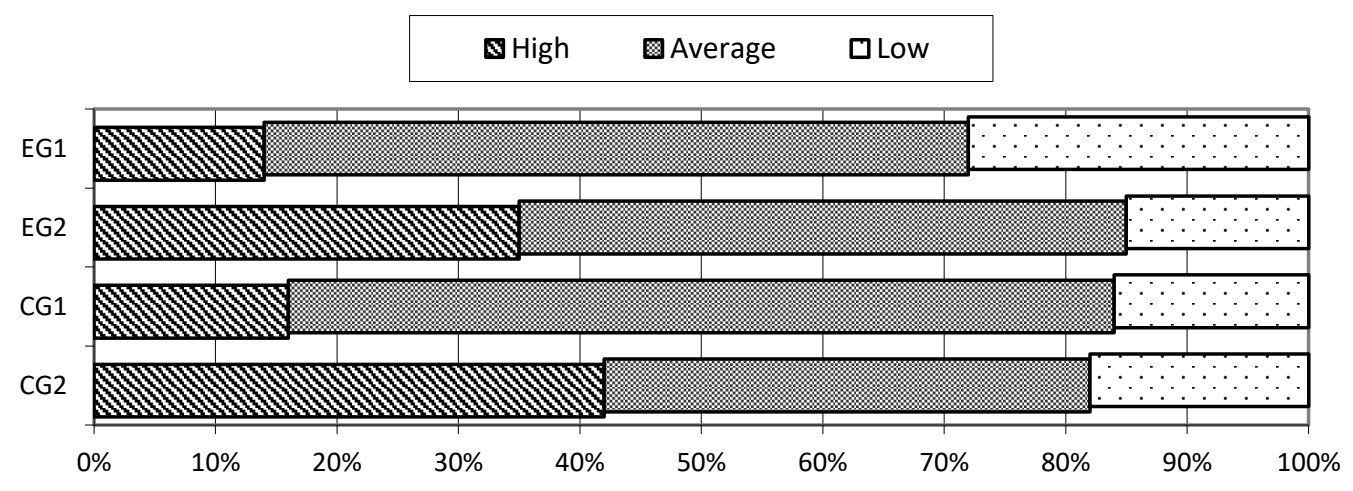

Figure 1. Number of participants (\%) by levels of physical indicator.

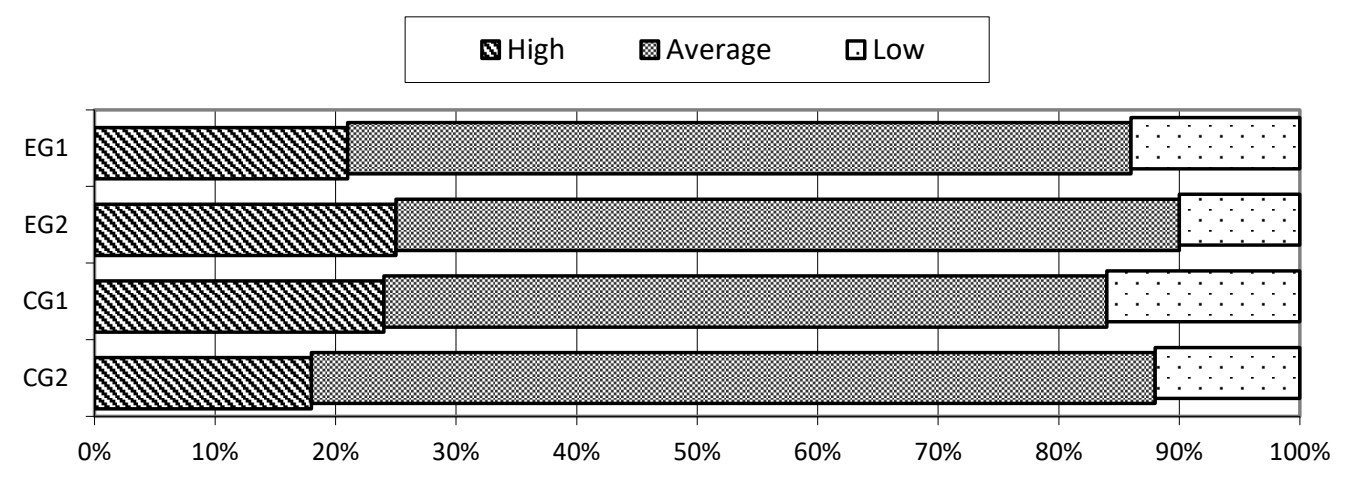

Figure 2. The number of participants (\%) by levels according to the health indicator.

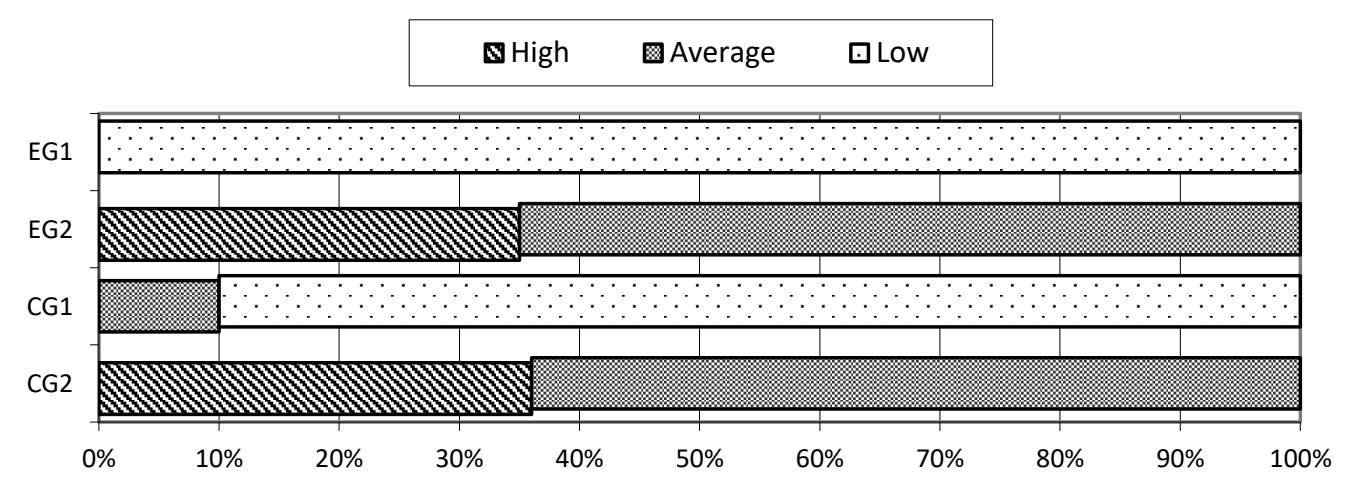

Figure 3. Number of participants (\%) by levels according to a proportional indicator. 


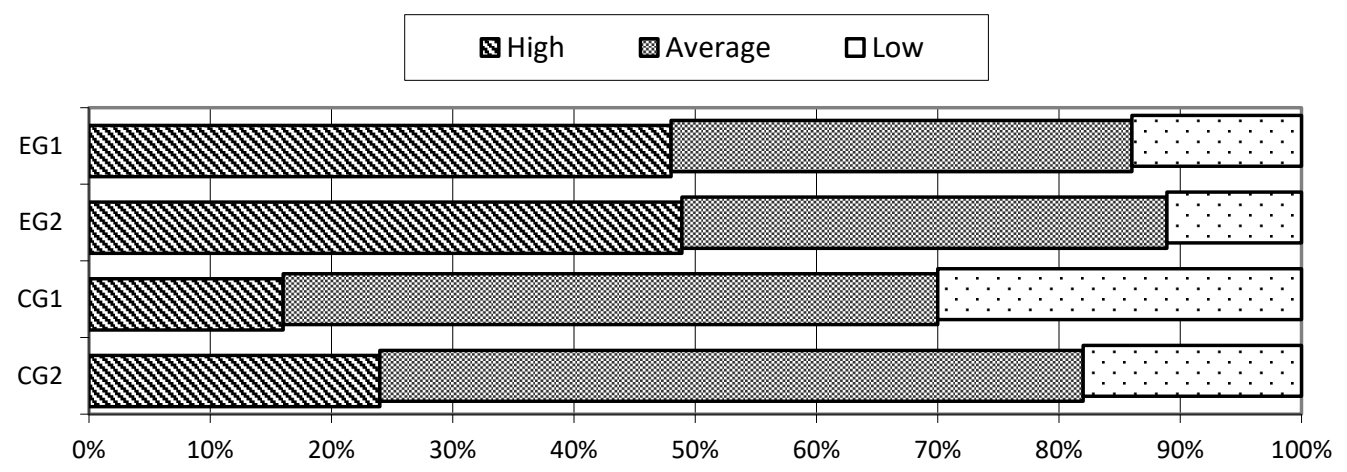

Figure 4. Number of participants (\%) by level by cognitive indicator.

The mathematical and statistical analysis of the chi square test of the obtained data on the number of participants (\%) by the levels of the physical indicator (Figure 1) showed no significant significance of differences between EG1 and CG1 ( $p>.05)$, as well as between EG2 and CG2 ( $p>.05)$. On the whole, over the entire EG and total CG, a comparative analysis revealed no significance of the difference ( $p>.05)$. However, before the experiment, the reliability between these groups was significant $(p<.05)$ in favour of the CG. This result shows that the differentiation of physical education in school in terms of the individual body mass index of schoolchildren had a positive impact on the physical development of students. In particular, a more detailed analysis showed particularly significant effectiveness in the development of endurance and dexterity in schoolchildren of the EG, compared with the CG.

The analysis of the obtained data on the number of participants (\%) by the levels of the health indicator (Figure 2) in mathematical-statistical processing showed no significant significance of differences between all groups $(p>$.05). Not significant shifts were recorded in EG2 in comparison with other groups. However, based on the results of mathematical-statistical analysis, it can be stated that this result may be random. Thus, according to the health indicator, the implementation of the author's differentiated conditions in physical education classes in school did not have an effect. This, in turn, was confirmed experimentally by comparing the groups of schoolchildren studied.

According to the proportional indicator, the number of participants (\%) by levels in EG1 and CG1 (Figure 3) is significantly different $(p<.01)$, and it is the same between EG2 and CG2 ( $>$.05). The experimental work did not affect the change in the body mass index of schoolchildren in CG1, CG2 and EG2, compared with the initial level. Nevertheless, in CG1, a significant result $(p<.01)$ was revealed between the initial and final diagnosis. This confirms the effectiveness of the implementation of the differentiation of physical education at school in terms of BMl of schoolchildren, in comparison with the training program without this differentiation. In the group CG1, where there was no differentiation of students by BMI in the physical culture lesson, there were 3 schoolchildren with overweight (10\%).

In the cognitive indicator, the number of participants (\%) in the levels in EG1 and CG1 (Figure 4) is significantly different, as in the previous indicator $(p<.01)$. A comparative analysis between EG2 and CG2 $(p<.05)$ also revealed a positive significant result in schoolchildren of EG2. Thus, it can be concluded that the separate education of schoolchildren, which has a significantly different body mass index, has a positive effect on the cognitive abilities of schoolchildren in the field of fitness activities. 


\section{DISCUSSION}

In the scientific literature there are experimental results on the reliable influence of physical activity on improving the physical fitness of schoolchildren in educational and extracurricular modes (Grieco et al., 2009; Oliveira et al., 2017). Experts prove the positive impact of the training process on various anthropometric and cardiovascular parameters in youth with overweight and obesity with high or moderate intensity (EspinozaSilva et al., 2019; Riso et al., 2016). Physical training for overweight and obese schoolchildren with various sports provides a positive effect in the proportional indicators of schoolchildren (Cvetković et al., 2018). Systematic physical activity, as experimental studies show, is the most effective means for the prevention of obesity at different levels of schoolchildren (Laguna et al., 2013).

In some studies, on improving the physical preparation of children to fulfil physical standards, in particular, the «Ready for Work and for the Defense» complex, the authors prove that for those who go in for physical culture it is necessary to organize a training process taking into account individually differentiated trajectories (Osipov et al., 2016; Tanaka et al., 2018). Experts prove that for each physical quality, an individual training of different functional intensity for adolescents of different physical levels and individual weekly physical activity should be compiled (Aoyama et al., 2018; Yarmak et al., 2018). This study proves that it is the differentiation of groups in school by body mass index that has a significant positive effect on physical development, in particular on improving the endurance and dexterity of schoolchildren. As the statistical results of the study show, schoolchildren with varying degrees of obesity perform theoretical and practical tasks in the lesson more effectively in an individually differentiated environment.

Unfortunately, most specialists do not pay due attention to the individually-differentiated approach to the harmonious and systematic development of not only the physical qualities of schoolchildren, but also their cognitive development (Magdalena et al., 2016). In the scientific literature, we were able to find only fragmentary studies related to the experimental testing of various forms of physical education (Donnelly et al., 2009; Grieco et al. 2009). However, these studies were carried out using comparative or motivationalvalue approaches to the formation of universal educational actions in the field of sports and fitness activities (Lee et al., 2007). In this direction, part of the research was focused on the differentiation of schoolchildren in the system: different ages, gender, level of functional preparedness and weekly motor activity of each participant (Tanaka et al., 2018). There are studies based on the individualization algorithm of the process of harmonious development of schoolchildren through the individualization of motivational-needful preferences for the use of various innovative technologies (Joyner et al., 2019). The presented study supplements these scientific works by substantiating the need for the application of individually differentiated technologies in physical education classes for 15-17 years. The originality of the approach through the differentiation of groups for physical education in terms of individual body mass index of schoolchildren 15-17 years old allows us to achieve the stated hypothesis of the study. The implemented experiment proves the practical novelty of the study by increasing the level of harmonious development of schoolchildren in the physical, proportional and cognitive aspects.

\section{CONCLUSIONS}

The study of the level of physical preparedness of schoolchildren of 15-17 years old through the development of endurance and dexterity showed that the introduction of the author's system of differentiation is reliably effective in comparison with other traditional and innovative programs for this age category. The mathematical and statistical analysis $(p<.01)$ between EG1 and CG1 proves the need for school to differentiate children into groups for physical education classes, not only by age, but also by individual body mass index. The study 
experimentally proved that the implementation of a differentiated environment for physical education in schoolchildren on the basis of their proportional characteristics has a positive effect on the activation of cognitive activity of schoolchildren. Differentiation of schoolchildren on the basis of an individual body mass index helps to reduce the number of schoolchildren with varying degrees of obesity.

The results of the experiment will be of interest to a wide range of specialists in the field of physical education and sports, as well as to parents whose schoolchildren have various degrees of obesity. The author's recommendations on the implementation of a differentiated approach in the lesson of physical education in school will increase the motivation of schoolchildren to set individual goals in the field of increasing the theoretical and practical fitness and health outcome. Further research will be aimed at studying the influence of the author's approach on different age and qualification categories. An experimental study will cover a larger sample of subjects with different individual capabilities and needs for the implementation of motor activity.

\section{DISCLOSURE STATEMENT}

There were no conflicts of interest.

\section{REFERENCES}

Aoyama, T., Tanaka, S., Tanaka, M., Okuda, M., Inoue, S., \& Tanaka, C. (2018). Association between age at onset of independent walking and objectively measured sedentary behavior is mediated by moderate-to-vigorous physical activity in primary school children. PLoS One, 13(9), e0204030. https://doi.org/10.1371/journal.pone.0204030

Aryana, M., Li, Z., \& Bommer, W.J. (2012). Obesity and physical fitness in California school children. Am Heart J, 163(2), 302-312. https://doi.org/10.1016/j.ahi.2011.10.020

Cvetković, N., Stojanović, E., Stojiljković, N., Nikolić, D., Scanlan, A.T., \& Milanović, Z. (2018). Exercise training in overweight and obese children: Recreational football and high-intensity interval training provide similar benefits to physical fitness. Scand J Med Sci Sports, 28(s1), 18-32. https://doi.org/10.1111/sms.13241

Dobashi, K. (2016). Evaluation of Obesity in School-Age Children. J Atheroscler Thromb, 23(1), 32-38. https://doi.org/10.5551/jat.29397

Donnelly, J.E., Greene, J.L., Gibson, C.A., Smith, B.K., Washburn, R.A., \& Sullivan, D.K. (2009). Physical Activity Across the Curriculum (PAAC): a randomized controlled trial to promote physical activity and diminish overweight and obesity in elementary school children. Prev Med, 49(4), 336-341. https://doi.org/10.1016/j.ypmed.2009.07.022

Espinoza-Silva, M., Latorre-Román, P.Á., Párraga-Montilla, J., Caamaño-Navarrete, F., Jerez-Mayorga, D., \& Delgado-Floody, P. (2019). Response of obese schoolchildren to high-intensity interval training applied in the school context. Endocrinol Diabetes Nutr, 66(10), 611-619. https://doi.org/10.1016/j.endinu.2019.05.005

Galan, Y., Koshura, A., Moseychuk, Y., Paliichuk, Y., Moroz, O., Tsybanyuk, O., \& Yarmak, O. (2018). Characteristics of physical conditions of 7-9-year-old schoolchildren within the process of physical education. Journal of Physical Education and Sport, 18(Suppl. issue 5). 1999-2007. https://doi.org/10.7752/jpes.2018.s5297

Grieco, L.A., Jowers, E.M., \& Bartholomew, J.B. (2009). Physically active academic lessons and time on task: the moderating effect of body mass index. Med Sci Sports Exerc, 41(10), 1921-1926. https://doi.org/10.1249/MSS.0b013e3181a61495 
Joyner, D., Wengreen, H., Aguilar, S., \& Madden, G. (2019). Effects of the FIT Game on Physical Activity in Sixth Graders: A Pilot Reversal Design Intervention Study. JMIR Serious Games, 7(2), e13051. https://doi.org/10.2196/13051

Khudolii, O., Ivashchenko, O., lermakov, S., Nosko, Y., \& Marchenko, S. (2019). Strength Abilities: Estimation of Immediate Training Effect of Strength Loads in Girls Aged 7 Years. Teoriâ ta Metodika Fizičnogo Vihovannâ, 19(2), 98-104. https://doi.org/10.17309/tmfv.2019.2.06

Laguna, M., Ruiz, J.R., Lara, M.T., \& Aznar, S. (2013). Recommended levels of physical activity to avoid adiposity in Spanish children. Pediatr Obes. 8(1), 62-69. https://doi.org/10.1111/j.20476310.2012.00086.x

Lee, S.M., Burgeson, C.R., Fulton, J.E., \& Spain, C.G. (2007). Physical education and physical activity: results from the School Health Policies and Programs Study 2006. J Sch Health, 77(8), 435-463. https://doi.org/10.1111/j.1746-1561.2007.00229.x

Magdalena, W., Urzędowicz, B., Motylewski, S., Zeman, K., \& Pawlicki, L. (2016). Body mass index and waist-to-height ratio among schoolchildren with visual impairment: A cross-sectional study. Medicine (Baltimore). 95(32), e4397. https://doi.org/10.1097/MD.0000000000004397

Nagovitsyn, R.S., Bartosh, D.K., Ratsimor, A.Y., \& Neverova, N.V. (2019). Modernization of Regional Continuing Pedagogical Education in the "School-College-Institute. European Journal of Contemporary Education, 8(1), 144-156. https://doi.org/10.13187/ejced.2019.1.144

Nagovitsyn, R.S., Miroshnichenko, A.A., \& Senator, S.Yu. (2018). Implementation of mobile pedagogy during continuous education of physical culture teachers. Integration of Education, 22(1), 107-119. https://doi.org/10.15507/1991-9468.090.022.201801.107-119

Nagovitsyn, R.S., Tutolmin, A.V., Maksimov, Y.G., Dimova, I.A., Karoyan, A.A., Skryabina, D.Y., \& Volkov, S.A. (2019). Motivation for physical activity of people of different ages. Gazzetta Medica Italiana - Archivio per le Scienze Mediche, 178(10), 799-806. https://doi.org/10.23736/S03933660.18.03965-7

Nagovitsyn, R.S., Volkov, P.B. \& Miroshnichenko, A.A. (2017). Planning of physical load of annual cycle of students', practicing cyclic kinds of sports, training. Physical education of students, 21(3), 126133. https://doi.org/10.15561/20755279.2017.0305

Nagovitsyn, R.S., Zekrin, F.H., Fendel', T.V., \& Zubkov, D.A. (2019). Sports selection in martial arts based on the harmonic stability of results at competitions. Journal of Human Sport and Exercise, 14(4proc), S867-S876. https://doi.org/10.14198//hse.2019.14.Proc4.49

Oliveira, A., Monteiro, Â., Jácome, C., Afreixo, V., \& Marques, A. (2017). Effects of group sports on health-related physical fitness of overweight youth: A systematic review and meta-analysis. Scand J Med Sci Sports, 27(6), 604-611. https://doi.org/10.1111/sms.12784

Osipov, A., Starova, O., Malakhova, A., Vonog, V., Zhavner, T., Salyamova, P., Struchkov, V., \& Kudryavtsev, M. (2016). Modernization process of physical education of students in the framework of implementation of the state strategy for the development of physical culture, sport and tourism in the Russian Federation. Journal of Physical Education and Sport, 16(4), 1236-1241. https://doi.org/10.7752/jpes.2016.04196

Rassadina, A.M. (1981). Goals and tasks of the All-Union "Ready for Work and for the Defense of the USSR" program complex. Feldsher Akush, 46(1), 16-19.

Riso, E.M., Kull, M., Mooses, K., Hannus, A., \& Jürimäe, J. (2016). Objectively measured physical activity levels and sedentary time in 7-9-year-old Estonian schoolchildren: independent associations with body composition parameters. BMC Public Health, 16, 346. https://doi.org/10.1186/s12889-016$\underline{3000-6}$ 
Şar N.Ş., Soyer F., \& Koç M. (2018). An analysis of psychological endurance and personality traits of individuals doing sports and not doing sports by various variables. Physical education of students, 22(2), 91-98. https://doi.org/10.15561/20755279.2018.0206

Song, P., Li, X., Gasevic, D., Flores, A.B., \& Yu, Z. (2016). BMI, Waist Circumference Reference Values for Chinese School-Aged Children and Adolescents. Int J Environ Res Public Health, 13(6), e589. https://doi.org/10.3390/ijerph13060589

Tanaka, C., Tanaka, M., \& Tanaka, S. (2018). Objectively evaluated physical activity and sedentary time in primary school children by gender, grade and types of physical education lessons. BMC Public Health, 18(1), 948. https://doi.org/10.1186/s12889-018-5910-y

Voloshina, L., Kondakov, V., Tretyakov, A., Kopeikina E, Cretu, M., \& Potop, V. (2018). Modern strategies for regulating the motor activity of preschool and school age children in the educational space. Pedagogy of Physical Culture and Sports, 22(2), 114-119. https://doi.org/10.15561/18189172.2018.0208

Yagotin, R.S., Degtyarenko, T.V., Bosenko, A.I., Plisko, V. \& Dolinsky, B. (2019). Criterion score of the physical and psychophysiological condition of students in the context of determining their individual adaptability to physical loads. Physical education of students, 23(1), 51-57. https://doi.org/10.15561/20755279.2019.0108

Yarmak, O., Blagii, O., Palichuk, Y., Hakman, A., Balatska, L., Moroz, O., \& Galan, Y. (2018). Analysis of the factor structure of the physical condition of girls 17-19 year-old. Journal of Human Sport and Exercise, 13(2proc), S259-S268. https://doi.org/10.14198/jhse.2018.13.Proc2.11

\section{@) $(\Theta \Theta \Theta$}

This work is licensed under a Attribution-NonCommercial-NoDerivatives 4.0 International (CC BY-NC-ND 4.0). 